University of Nebraska - Lincoln

DigitalCommons@University of Nebraska - Lincoln

Journal for the Advancement of Developing

Economies

Economics Department

2012

\title{
Impact of Work Values and Individual Attributes on Citizenship and Task Performance: A Test in a Developing Country Context
}

Anil Chadrakumara

University of Wollongong, anilc@uow.edu.au

Follow this and additional works at: https://digitalcommons.unl.edu/jade

Part of the Econometrics Commons, Growth and Development Commons, International Economics Commons, Political Economy Commons, Public Economics Commons, and the Regional Economics Commons

Chadrakumara, Anil, "Impact of Work Values and Individual Attributes on Citizenship and Task Performance: A Test in a Developing Country Context" (2012). Journal for the Advancement of Developing Economies. 14.

https://digitalcommons.unl.edu/jade/14

This Article is brought to you for free and open access by the Economics Department at DigitalCommons@University of Nebraska - Lincoln. It has been accepted for inclusion in Journal for the Advancement of Developing Economies by an authorized administrator of DigitalCommons@University of Nebraska - Lincoln. 


\title{
Impact of Work Values and Individual Attributes on Citizenship and Task Performance: A Test in a Developing Country Context
}

\author{
Anil Chadrakumara \\ University of Wollongong
}

\begin{abstract}
This study examined the impact of work values and individual characteristics on organizational citizenship behavior (OCB) and task performance (TP). Based on the arguments of Social Capital Theory, a theoretical foundation was developed to use work values as antecedents of $O C B$. Analyzing 416 responses from Sri Lankan manufacturing sector employees, it was found that gender and employment category were related to citizenship performance, while level of education was related to task performance. More importantly, the impact of work values (work norms, work ethics, and intrinsic values) on $O C B$ was found to be more significant than that of demographic factors. Overall, the study contributes to individual attributes and work value theories of $O C B$ by providing empirical evidence to understand how strongly individual attributes and work values affect $O C B$.
\end{abstract}

Keywords: Work Values, Citizenship Performance, Task Performance, Developing Countries, Sri Lanka

\section{INTRODUCTION}

There has been an enduring challenge for organizations to encourage behaviors that serve the organization's goals. Some of these behaviors are not easily monitored or explicitly rewarded (Korsgaard, Meglino, Lester, Jeong, 2010; Chiaburu \& Byrne, 2009). Early interest in unrewarded organizational behaviors (Katz \& Kahan, 1966) developed into a deeper understanding of what motivates such pro-social behavior (Organ, 1988) and the definition of organizational citizenship behavior (OCB). As such, organizations rely on their members to perform numerous behaviors that go beyond the formal employment contract and are not readily monitored or enforced (Korsgaard et al, 2010; Podsakoff, Whiting, Podsakoff, \& Blume, 2009). Sparrow (2006) argued the need to incorporate the study of values into the analysis of OCBs to reflect psychological, emotional and attitudinal states and salient organizational behaviors. A stream of research has since linked cultural work values to an understanding and prediction of the behavior and performance of individuals at work (e.g. Varma et al., 2009; Gahan \& Abesekera, 2009; Gerhart, 2008; Kirkman, Lowe \& Gibson, 2006; Sparrow \& Wu, 1998). Such works have shown that cultural values do indeed play a role in encouraging or dissuading OCBs.

However, the motivations behind such behaviors have not been adequately studied in different contexts (Korsgaard et al., 2010; Chiaburu \& Byrne, 2009). Little is known about the predictors and mechanisms that sustain unmonitored and unrewarded pro-social behaviors or OCBs. In 
particular, the literature demonstrates a lack of theoretical and empirical understanding about the impact of work values on OCB. A number of researchers have also highlighted the need to examine the impact of individual characteristics and work values on OCBs (e.g. Moon, Kamdar, Mayer, \& Takeuchi, 2008; Furnham et al, 2005; Feather, 1995; Podsakoff, MacKenzie, Paine, \& Bachrach, 2000). Furthermore, some scholars have also stressed the need to identify determinants of individual differences in OCB in relation to work values and ethics (e.g. Moon et al., 2008; Furnham, Petrides, Tsaousis, Pappas, \& Garrod, 2005; Borman, Penner, Allen, \& Motowidlo, 2001; Podsakoff et al., 2000). However, most studies have looked at rather narrowly defined work value models or at two or three-dimensional models (e.g. extrinsic values and intrinsic values; individualism and collectivism). In this study, we intend to select broad categories of work values with particular references to industrial culture values which are important for developing countries. As such, we address two major research issues in this study:

1. Do work values act as antecedents of OCBs? If so, what are those work values and their relative significance?

2. What theoretical frameworks are relevant to the exploration of links between work values and citizenship performance?

Previous researchers have stressed the need to identify determinants of individual differences in OCB in relation to individual characteristics, work values, (Moon at al., 2008; Furnham et al., 2005; Borman et al., 2001; Podsakoff et al., 2000) and developing countries (Chandrakumara and Sparrow, 2004; Budhwar and Debrah, 2001). By providing theoretical support and some empirical evidence, this study intends to provide a significant contribution to the theories and practices of work values and OCB. In addition, this study intends to provide theoretical and empirical support to the assertion that unique human resource values and capabilities could be considered as sources that create competitive advantages (e.g. Organ \& Lee, 2008; Paine \& Organ, 2000), which is an increasingly critical attribute of heightened competition in the global market place (Tierney, Bauer, \& Potter, 2002; Kidder, 2002). As such, this study would contribute to resource-based theory and resource-based view of a company.

More importantly, our theoretical framework and argument on the influence of work values on CTP is mainly based on Social Capital Theory because values and beliefs can be considered as one set of the determinants of social capital (Fukuyama, 1995; Pantoja, 1999) at an individual level, which shapes volunteerism dimension of social capital. Citizenship behavior consists of a series of such voluntary behaviors. As such, consequences of social capital may be manifested in organizational performance (e.g. Aldridge, David \& Sarah, 1992). Some indicators of organizational performance are citizenship and task performance. Therefore, our contribution to the advancement and application of Social Capital Theory would also be significant.

\section{THEORETICAL LENS - THE RESOURCE BASED VIEW OF THE FIRM}

For the empirical part of this study we selected a developing country in south Asia for a number of reasons. First, with regard to attracting foreign direct investment (FDI) and addressing the issue of applicability of management practices, developing countries are considered as useful locations (e.g. Aycan, Al-Hamadi, Davis, \& Budhwar, 2007; Fariba, 2006; Chandrakumara \& Sparrow, 2004; Budhwar \& Debrah, 2001; Sparrow \& Wu, 1998). 
Second, Sri Lanka, which was known as Ceylon, is an emerging and fast developing country in South Asia (Reade \& McKenna, 2007). While South Asia accounts for more than 32 percent of the world population, Sri Lanka's population exceeds 20 million. Sri Lanka is considered to be South Asia's most open economy, which is sometimes known as 'the Gate Way to South Asia' by foreign investors (Chandrakumara \& Budhwar, 2005). Since the end of prolonged civil war in 2009, Sri Lanka's economy has been growing at an average growth rate over 7 percent. Its economy has been very resilient to both internal and external shocks over the last two decades. For past two decades, the country has implemented many economic reforms, most prominently in trade, taxation, privatization, and enhancing the flexibility of the labor market. The recently released results of the 2012 Change Readiness Index has ranked Sri Lanka in the 22nd place among 60 developing and emerging world economies and first among South Asian countries. The survey was conducted by KPMG International in collaboration with researchers from the Overseas Development Institute (ODI). With the steady expansion of business sector in Sri Lanka, there has been increasing interest in understanding appropriate management policies and practices relevant to private and public-sector organizations.

Third, the sociocultural background factors highlight the fact that South Asian countries, despite their geographical proximity, are not necessarily very similar due to significant differences in their cultural heritage, managerial philosophy, and development strategies. For example, Sri Lankan management practices evolved from the British system prior to Sri Lanka's political independence and have adopted Western management practices backed up by Westernized education (Nanayakkara, 1992), Indian management practices have developed a distinct Indian flavor (Sparrow \& Buddwar, 1997; Garg \& Parikh, 1988). Similarly, Sri Lankan culture and people have been influenced by cultures of other countries and organizations. For example, Sri Lankans exhibit many Asian traits in their family and other social interactions, but informal organizational settings and businesses, they tend to mix Asian traits with Western management philosophies and practices (Chandrakumara \& Sparrow, 2004). Theoretical and empirical evidence indicate that management practices values, and employee behavior seem to diffuse through channels such as management literature, consultancy, training and education, international conventions and laws, and multinational corporate management (Selmer and De Leon, 1996; Roe and Ester, 1999). With regard to cultural emphasis on values and ethics, developing countries are considered to represent useful locations to examine work behaviors (Aycan et al., 2007; Fariba, 2006; Budhwar \& Debrah, 2001). Therefore, Sri Lanka provides an appropriate outlet for exploring the complexity of work values and their impact on employees' behavior and performance.

\section{THEORETICAL BACKGROUND}

We begin with a brief review of the literature on OCB and work values, and then explore the link between the two concepts in order to identify appropriate variables and propositions for the study. The original definition of organizational citizenship behavior (OCB) posited by Organ (1988) was, "individual behavior that is discretionary, not directly or explicitly recognized by the formal rewards system, and that in the aggregate promotes effective functioning of the organization," (p. 4). OCB reflects voluntary, proactive, and non-prescribed actions taken by employees in an effort to improve organizational performance (Hunt, 2002). Understanding what motivates OCBs is important for practicing managers as organizations expect their members to 
perform numerous behaviors that extend beyond the formal employment contract (Korsgaard et al., 2010; Podsakoff et al., 2009). If such behaviors are embedded in cultural and work values, they can be considered as sources that create competitive advantage in the global market place (Organ \& Yeon Lee, 2008; Tierney et al., 2002; Paine \& Organ, 2000; Kidder, 2002) because: cultural work values are enduring characteristics of individuals (Grant, 2008), (b) they might provoke unrewarded and unmonitored pro-social behaviors in organizations (Gagne \& Deci, 2005; Smeesters, Warlop, Van Avermaet, Corneille, \& Yzerbyt, 2003), and (c) OCBs shape the organizational, social, and psychological context that serves as the critical catalyst for task activities and processes (Borman \& Motowidlow, 1993).

The literature provides various definitions of values. Rokeach (1973) defines a value as, "an enduring belief that a specific mode of conduct or end-state of existence is personally or socially preferable to an opposite or converse mode of conduct or end-state of existence," (p. 5). Super (1980) defines a value as, "an objective, either a psychological state, a relationship, or material condition that one seeks to attain," (p. 130). Over the years, a great deal of research has been devoted to the study of values in relation to work (Gahan \& Abesekera, 2009; Roe \& Ester, 1999; Sagie, Elizur, \& Koslowsky, 1996).

A work value, which is a specific context to which values can be applied, can be defined as the importance individuals give to a certain outcome obtained in a work context (Elizur, 1984). According to Ros, Schwartz, Surkiss (1999) work values are beliefs pertaining to desirable endstates (e.g. high pay) or behaviors (e.g. working with people). A widely used approach classifies work values as intrinsic and extrinsic (Herzberg, 1966; Wollack, Goodale, Wijting, \& Smith, 1971). Based on his extensive literature review, Elizur (1984) presented two basic facets of work values. The first concerns the modality of the work outcome, i.e. whether or not it is instrumental (obtained a desired end such as pay for performance). This modality may be cognitive (a belief system regarding appropriate behavior such as achievement, meaningful work, contribution to society), or affective (values that deal with feelings or emotions such as enjoyments, relationships). He also drew attention to the system performance contingency (system wide or common incentives such as benefits plan, services such as transportation). Despite a plethora of different labels, most researchers identify the same two or three types of work values: extrinsic values, intrinsic values, and social or relational values. Ros et al (1999) found that these three types of work value correspond with instrumental, cognitive and affective values, respectively. They developed a generic model of general values and work values in which both general and work values influence work or occupational activities such as career choices, job application, or task performance.

Important "societal and others' oriented" work values include protestant work ethic (Preston, 1987; Brief \& Aldag, 1994; Furnham, 1996); the Confucian work ethic which has shaped Japanese work values such as hard work, respect for time, and drive to accumulate wealth (Coates, 1987); and need for achievement, benevolence and power (Elizer, 1984; Schwarts, 1992; Hartman \& Samra, 2008;). Such values impact attitude, choice, judgment, and conduct (Feather, 1995).

A stream of research has also demonstrated that social value orientations influence cooperative behavior (see Smeesters, Warlop, Van Avermaet, Corneille, \& Yzerbyt, 2003 for a review). 
Social value orientations are dispositional variables and have received substantial attention in studies on cooperative behavior (Allison \& Messick, 1990). Three kinds of social value orientations have been identified by Smeesters et al. (2003). The first of which is pro-social (based on a desire to expend effort to benefit other people) and the last two of which are pro-self: a pro-social orientation (maximizing joint outcomes and equality of outcomes); an individualistic orientation (maximizing own outcomes with little or no consideration about others); and a competitive orientation (maximizing own outcomes relative to other's outcomes). A number of work norms are important to pro-social behaviors. While work values refer to import work outcomes, work norms refer to what should be done, what others expect from us, and what we expect from others (Sagie et al., 1996). Two generic work norms have been identified in the work value literature: entitlement and obligation (Harpaz, 1986; Sagie \& Weisberg, 1996). Entitlements are benefits or rewards that individuals expect within the work framework. Obligations refers to the employees' perception of what is required of them within the work framework (e.g. punctuality, cooperate with others).

Finally, Motowidlow and Van Scotter (1994) have reported a significant positive relationship between internal locus of control and citizenship performance. Locus of control is defined as a generalized belief that rewards reinforcement and claims that outcomes in life are controlled either by oneself or factors outside oneself (Rotter, 1966). Work locus of control can be considered either as a value or as a component of personality. When measured as a value, Spector (1982) noted that those with the internal locus of control tend to exhibit greater personal career effectiveness, exert greater effort, perform better on the job, and demonstrate greater job satisfaction than externals. It predicts some aspects of OCB such as altruism, courtesy, and sportsmanship (Podskoff et al., 2000; Konovsky \& Organ, 1996). Cross-cultural researchers note the conceptual similarities between measures of external locus of control and the naturesubjugation values of Kluckhohn and Strodbeck (1961).

Based on this evidence, five categories of work values and ethics (work orientations) are considered to represent variables appropriate for exploring links with OCBs:

1. Extrinsic values

2. Intrinsic values

3. Work ethics and beliefs

4. Work norms

5. Work-locus of control

In order to represent these variables, some researchers have used the term 'work values' (e.g. Dose, 1997), while some others have used the term 'work ethics' (Heller, 1997). In this study, the term "Work Values" or 'Work Values and Ethics' is used alternatively to represent these five variables.

With regard to addressing the issue of changes in work values, researchers have attempted to take transformations in important work-related behaviors into account by studying changes in the "meaning of work" (MOW, 1987; England \& Harpaz, 1990; Ruiz-Quintanilla \& England, 1996; Noon \& Blyton, 1997), "work related ethics and beliefs" (Buchhols, 1978, Dickson \& Buchhols, 1977) and "work values" (Wollack et al., 1971, Sagie et al, 1996, Roe \& Ester, 1999). In this 
study, we examine a number of work values, ethics, beliefs, and norms that have been used by previous researchers. The selection is based both on previous empirical work and a contextual emphasis on the need for developing industrial culture values in Sri Lankan context (e.g. Nanayakkara, 1992).

Based on this theoretical and empirical support, four major propositions were developed for this study:

1. Employees who are oriented more towards intrinsic values engage in OCBs than those who are oriented more towards extrinsic values.

2. Employees who are oriented towards more positive work ethics, beliefs and norms engage in OCBs than those who are less oriented towards such work values.

3. Employees who are oriented more towards internal work locus of control engage in more OCB activities than those who are oriented towards external locus of control.

4. There is a positive relationship between OCB and task performance.

This study is designed to make contributions to OCB and work value theories and to develop country context knowledge. It provides both empirical evidence and a theoretical explanation of those work values that can be considered as motivators or antecedents of OCBs. It also contributes to the growing body of knowledge and empirical findings relevant to work values and OCBs in the context of developing countries.

\section{METHODOLOGY}

\subsection{Sample}

The sample was drawn from employees in one sector, the manufacturing sector, in order to control for the effect of different organizational sectors on OCB. Six companies participated in the study. This industrial sector represents about $7.4 \%$ of employed labor force in Sri Lanka.

A total of 416 out of 650 questionnaires distributed were returned in usable form, representing a response rate of 64 percent. Two hundred and one (201) respondents are from foreign-invested firms (FIF) with 215 participants from domestic firms (DF). The disproportionate stratified random sampling method was used to select respondents in order to ensure different categories of employees were included in the sample (e.g. Sekaran, 2000). Fifty four percent of respondents were female and 76 percent were aged 35 years or below. Level of education was up to G.C.E $(\mathrm{O} / \mathrm{L})$ for 48 percent respondents of the sample with 36 percent having G.C.E (A/L) education. This is in line with national level data on the level of education in the Sri Lankan manufacturing sector. The operator and technical level employment category represented forty percent of respondents. Managerial and professional levels represented 10.6 percent and 7.7 percent respectively.

\subsection{Independent Variable Measures and Statistical Optimization}

A work values scale was developed by the researcher to represent five categories of work values and ethics (work norms, work ethics and beliefs, intrinsic values, extrinsic values, and work locus of control). These were based on a number of previous measurement scales. Items were 
selected to avoid overlapping of constructs, to have clarity of meaning, and to consider the value of factor loading (if available), and to have contextual relevancy for use in Sri Lanka. The questionnaire consisted of 45 items. All items had a seven point (0-6) subjective self-report format and were translated into a local language and back translated to further validate the instrument. It was pilot-tested through personal interviews with 12 employees, including five executives selected from the sampling context, to enable a final check on the clarity and appropriateness of language. A range of statistical tests were then performed to optimize items. The first set of items, refined into sub-scales through subsequent principal component analysis, was derived from core measures in the following areas: list the areas here!

\subsection{Work Norms, Work Ethics and Work Beliefs}

Items relevant to work norms, work ethics and beliefs were selected to represent six constructs from the MOW (MOW, 1987) and Buchholz's scales $(1977 ; 1978)$. These values are associated mainly with industrial sector values.

\subsection{Intrinsic and Extrinsic Work Values}

The scale was derived principally from Wollack et al.'s (1971) scale that assesses five values. Items were selected to represent both intrinsic and extrinsic values, which are representatives of content and context of work. The values that are associated with the context of work consist of high salary, job security, pleasant working environment and good fringe benefits (Furnham, 1997). The inclusion of these work content and context values can be justified in the context of developing countries because Furnham (1997) notes that it is quite possible that fairly large proportions of workers in developing countries are context oriented, as they strive to better the livelihood of themselves and their families.

\subsection{Work Locus of Control (WLC)}

Items were selected from Spector's (1982) scale. The work values scale was subjected to principle component analysis using Varimax rotation. The decision criteria adopted for factor loading was 0.40 to minimize cross-loading and facilitate Rotated Component Matrix. Given the relatively broad construct of work values and small number of items (most scales have less than 10 items), a coefficient of alpha in 0.60 s can be regarded as sufficiently reliable (Taris and Feij, 2001; Briggs and Cheek, 1986) and is considered reasonable for scales measuring broad constructs such as values (Singelis et al., 1995). A five-factor solution was therefore accepted as having reasonably reliable structure. The Cronbach's Alpha coefficients for the five factors are Work Norms $=0.62$, Work Ethics and beliefs $=0.62$, Extrinsic values $=0.66$, Growth values $=0.61$, Work locus of control $=0.61$. The reliability indices are consistent with many other similar subscale studies (e.g. Furnham, 1996; Wollack et al., 1971; Taris and Feij, 2001). For example, Farnham's (1996) study reports an alpha coefficient of 0.65 and 0.66 respectively for work ethics and organizational belief system sub scales. With regard to extrinsic and intrinsic values based on Wollack et al., (1971) and Pelled and Hill (1997) reported alpha coefficients of 0.50.

\subsection{Dependent Variable Measure and Statistical Optimization}




\subsubsection{Citizenship Behavior}

Citizenship behavior was measured using Smith, Organ, Near's (1983) citizenship performance scale. Coleman and Borman (2000) argued that Smith's citizenship performance indicators are compatible with their categorization of citizenship/contextual performance dimensions as interpersonal (CPI), organizational (CPO), and job/task activities (CPJ). Item selection was kept consistent with the contextual performance taxonomy proposed by Motowidlo and Borman (1997) i.e. volunteering, persisting, helping, following rules and procedures, and endorsing organizational objectives.

\subsubsection{Task performance (TPE)}

A ten-item scale developed by Goodman and Suyantek (1999) was used. This scale was selected because it could be used for all categories of employees in the sample and also because its items are comparable with other scales used to measure task performance (e.g., Wayne et al., 1997; Bishop, Scott, \& Burroughs, 2000). These dependent performance variables were rated by supervisors. Both of the scales were then subjected to principal component analysis separately using a similar approach explained above under the work values scale. Table 1 presents the results of factor analysis of the OCB scale.

This scale's items fall into three clear factors, which were labeled as citizenship performance towards interpersonal relationship (CPTIR), citizenship performance towards the task (CPTT), and citizenship performance towards the organization (CPTO). The Cronbach's Alpha coefficients for the three OCB and one TP dimensions are citizenship performance towards interpersonal relationship $($ CPTIR $)=0.84$, citizenship performance towards task $(\mathrm{CPTT})=0.78$, citizenship performance towards organization $(\mathrm{CPTO})=0.42$, and task performance $=0.89$. Given the low reliability of items on the third factor of Citizenship performance towards the organization, it was dropped from further analysis.

\section{RESULTS}

The main focus of this study was to examine the impact of work values on OCBs. The independent variables consist of the demographic measures and the five work values. These are regressed onto the three remaining performance outcomes: citizenship performance towards interpersonal relationship, citizenship performance towards task, and task performance regressions. These performance outcomes were run for the overall sample and for each of the foreign invested and the domestically owned samples.

\subsection{Correlation between Work Values OCB}

Before embarking on the regression analysis, we examine the level of correlation. Discriminant validity could be observed across the variables, notably by the negative correlation between external work locus of control and intrinsic values and by the positive correlation between internal locus of control and external work locus of control (see Table 2). 
Table 2 shows that employees have relatively high orientation towards work norms (Mean 5.43; $\mathrm{SD}=0.53$ ), work ethics (Mean 4.99; $\mathrm{SD}=0.58$ ), and intrinsic values (Mean 4.20; $\mathrm{SD}=0.77$ ). Moderate and relatively low orientations are indicated for extrinsic values (Mean 3.63; $\mathrm{SD}=$ 1.24) and work locus of control (Mean 2.93; $\mathrm{SD}=1.53$ ). Table 2 shows a number of significant relationships between work values and OCB dimensions.

There are positive relationships between OCB and relatively higher scores of work norms, work ethics, and intrinsic values, while negative relationships exist between external work locus of control and OCB. A significant positive relationship between OCB and TP is also displayed in Table 2.

\subsection{Regression Analysis}

Hierarchical regression analysis was performed in order to examine the impact of work values on OCB by controlling for the effect of demographic factors on OCB in the second step of the hierarchical regression analysis. Table 3 displays the results of regression analysis using the whole sample and the two samples of foreign-invested firms and domestic firms.

Table 3 demonstrates that demographic factors account for 9 percent variation in citizenship performance towards interpersonal relationships (CPTIR) in foreign-invested firms $(\beta=0.09$; $\mathrm{P}$ $>0.05)$ and 11 percent variation in citizenship performance towards tasks (CPTT) in domestic companies $(\beta=0.11 ; \mathrm{P}>0.05)$. This is mainly reflected by male employees' involvement in CPTIR in foreign-invested firms and their involvement in CPTT in domestic firms. Higher education seems to have more of an impact on task performance than on OCB. Managerial $(\beta=$ $0.18 ; \mathrm{P}>0.05)$ and professional $(\beta=0.27 ; \mathrm{P}>0.05)$ employees' involvement in CPTT in foreign-invested firms is found to be statistically significant. In addition, the clerical level of employees'

Table 1: Contextual Task Performance Items and Factor Loading

\section{Items}

Factor Loading

$\begin{array}{llll}1 & 2 & 3 & \text { TP1 }\end{array}$

CPI2- Help others when their workload increases

0.778

CPI1- Help others with their work when they have been

CPI3 Take initiatives to orient new employees to the 0.688

CPJ1 Volunteers to do things not formally required by the job

0.623

CPJ3- Make innovative suggestions to improve the unit.... 0.709

CPJ2- Offer suggestions to improve operations/activities

CPJ4- Willingly attend functions not required by the 0.530

CPO3- Express resentment with changes introduced by the 0.634 
$\begin{array}{ll}\text { CPO4- Exhibit attendance at work beyond the norm } & 0.607\end{array}$

$\begin{array}{ll}\text { CPO1- Exhibit punctuality in arriving at work } & 0.605\end{array}$

TPE2- Meet criteria for performance

0.85

TPE6- Handle tasks with proficiency and be competent in doing

0.82

TPE3- Demonstrate expertise in all job-related tasks

TPE1- Achieve the objectives of the job

TPE8- Perform well in the overall job by carrying out tasks as

TPE5-Could manage more responsibility than typically

TPE7- Feel suitable for a higher level role

Cumulative Variance explained

Mean

Standard deviation

$\begin{array}{llll}0.84 & 1.06 & 0.96 & 0.69\end{array}$

Alpha (supervisor -rating)

$\begin{array}{lllll}0.83 & 0.78 & 0.42 & 0.89\end{array}$

Note: Only coefficients $>0.50$ are shown. Some items' wordings have been shortened. The rating scale $0-6$.

Table 2: Mean, Standard Deviation, Alpha Coefficients, and Correlations Between Work Values and CTP measures

\begin{tabular}{|c|c|c|c|c|c|c|c|c|c|c|c|}
\hline & Mean & SD & Alpha & 1 & 2 & 3 & 4 & 5 & 6 & & 8 \\
\hline 1. Work Norms & 5.43 & 0.53 & .62 & 1 & & & & & & & \\
\hline 2. Work Ethics \& Beliefs & 4.99 & 0.58 & .62 & .12 & 1 & & & & & & \\
\hline 3. Extrinsic Values & 3.63 & 1.24 & .66 & -.01 & .13 & 1 & & & & & \\
\hline 4. Intrinsic Values & 4.20 & 0.77 & .61 & .13 & .17 & .12 & 1 & & & & \\
\hline 5. Work Locus of Control & 12.93 & 1.55 & .62 & -.01 & .06 & $.14^{*}$ & $-.25^{*}$ & 1 & & & \\
\hline 6. CPTIR & 4.26 & 0.84 & .83 & $.27 * *$ & $.19^{*}$ & .04 & .14 & -.06 & 1 & & \\
\hline 7. CPTT & 3.41 & 1.06 & .78 & $.16^{* *}$ & .04 & -.01 & .08 & -.07 & $.24 * *$ & 1 & \\
\hline 8. Task Performance & 4.29 & 0.69 & .89 & .29 & $.24 * *$ & .01 & $.11 *$ & -.10 & $.42 * *$ & $.42 * *$ & 1 \\
\hline
\end{tabular}

** Correlation is significant at the 0.001 level * Correlation is significant at the 0.01 level

involvement in CPTIR in both foreign-invested firms $(\beta=0.24 ; \mathrm{P}>0.05)$ and local companies $(\beta$ $=0.16 ; \mathrm{P}>0.05)$ is also significant. 
With regard work values-OCB link, the impact of the dimension of work norms is equally important for OCB in both foreign-invested firms and domestic companies. However, it was found that the impact of work ethics on OCB is more important in local companies $(\beta=0.21 ; \mathrm{P}$ $>0.01)$ than in foreign-invested firms $(\beta=0.08 ; \mathrm{P}>0.16)$. While an extrinsic work value is not related to any indicators of OCB and TP in both local and foreign-invested firms, intrinsic values are correlated with citizenship performance towards interpersonal relationships in foreigninvested firms. As predicted, the relationship between external work locus of control and OCB is negative for all performance criteria, but the impact is statistically significant only in the case of TP in local companies $(\beta=-0.20 ; \mathrm{P}>0.05)$. Overall, while the impact of work norm on OCB is significant for both local companies and FIF, the impact of work ethics on OCB is more significant for local companies. Furthermore, the impact of intrinsic values on OCB is significant in foreign invested firms. These differences are an important finding.

\section{DISCUSSION}

This study has examined the impact of work value orientations and demographic factors on OCB and performance (TP). The evidence shows that both demographic factors and work value dimensions are related to OCBs in both local and foreign invested firms. However, the relative impact of work values on OCB is more significant than that of demographic factors. It was found that male employees' involvement in OCB is more significant than that of female employees. Gender, education and employment category were found to be significant in OCB. The impact of higher level of education on task performance is also evident in this study (but not on OCB). The findings also suggested that managerial and professional employees' involvement in citizenship performance towards task is statistically significant only in foreign-invested firms. For clerical level employees' involvement in citizenship performance towards interpersonal relationships is significant in both foreign-invested firms and local firms.

Although previous researchers have stressed the need to identify determinants of individual differences in OCB in relation to work values and ethics (e.g. Moon et al., 2008; Furnham et al, 2005; Borman et al., 2001; Podsakoff et al., 2000), most studies have looked at rather narrowly defined work value models or at two or three-dimensional models (e.g. extrinsic values and intrinsic values; individualism and collectivism). In this study, we have measured five broad categories of work values. The findings revealed that work norms (humanistic beliefs or individual growth-oriented work norms), work ethics (organizations and positions oriented work ethics and beliefs), intrinsic values (status and security oriented upwards striving), and external work locus of control (negatively related) were all seen to be important in influencing OCB and thus substantially supporting our first three propositions. It was evident that there some differences between FIF and DF with regard to the proposed link between work values and CTP. This requires further theoretical understanding of rationality behind employees' behavior in FIF and domestic firms. Our fourth proposition was related to the link between citizenship and task performance. In line with theoretical and empirical evidence on the positive relationship between citizenship and task performance (e.g. MacKenzie, Podsakoff, \& Fetter, 1991; Werner, 1994), the empirical results of this study also provide strong evidence on the positive relationship between OCB and TP. Similarly, while the impact of intrinsic values is related to citizenship performance towards interpersonal relationships (CPTIR) in foreign-invested firms, work ethics is positively related to both CPTT and CPTIR in local firms. 
We argued that researchers need to trace differences in performance outcomes such as OCB and Task Performance to important antecedents. In relation to the field of IHRM, some of these antecedents may simply reflect the demographic mix of workforces (which may vary across country or across labor markets). Other antecedents, such as work values, may be more culturallyembedded. To some extent, although the culturally-embedded nature of OCB is often understated, our findings could be used to reemphasize the argument. We note that there are comparable findings relating to the relationship between individual growth-oriented work norms, work ethics and beliefs, and status and security oriented upwards striving and OCB. These can be found in studies by Sparrow and $\mathrm{Wu}$ (1998), Merrens and Garrett (1975), Hackman and Walton (1986), Claes and Ruiz-Quintanilla, (1995); MOW, (1987), and England and Harpaz (1990). For example, Sparrow and $\mathrm{Wu}$ (1998) found that organizational commitment and job satisfaction were associated with 'activity doing' and 'individualistic' values, which are comparable to the work ethics and beliefs and work norms dimensions used in this study.

In addition, Merrens and Garrett (1975) found that high Protestant ethic subjects spent more time working and producing more output than those subjects with a low Protestant ethic. Theoretical evidence also suggests that employees with a high level of growth and achievement values (Intrinsic values) tend to be more actively involved in contextual performance activities and thereby increased task performance than those who have lower level achievement and growth values. For example, Hackman and Walton (1986) note that individuals with a strong need for growth should respond eagerly and positively to the opportunities provided by enriched work. Individuals with a low need for growth, on the other hand, may not recognize the existence of such opportunities or may not value them or find them threatening. As such, the finding of this study that work values, work ethics, and intrinsic values influence OCBs can be supported by some similar findings in the literature.

The finding that the impact of the external work locus of control is negatively associated with both OCB (overall) and TP (in local firms) is also supported by previous studies (e.g., Reitz and Jewell, 1979; Motowidlo and Van Scotter (1994). For example, Motowidlo and Van Scotter (1994) reported a significant correlation $(r=.26)$ between internal locus of control and OCB. Theoretical evidence also indicates that internals exhibit greater personal career effectiveness, exert greater effort, perform better on the job and demonstrate greater job satisfaction than externals (Spector, 1982).

To guide this research, we think that the findings of this study provide useful theoretical and empirical evidence to understand how strongly individual attributes and work values and ethics affect OCB and thereby contribute to work values and individual attributes theories of OCB and TP. A number of practical implications can also be found in this study. Firstly, HR managers can consider employees work and value orientations when they select people for positions that require more OCB activities. The findings of this study revealed that managerial level employees' propensity to involve in contextual performance is relatively higher than that of clerical, manual, and operator level employees. Secondly, HR managers may also design training and development programs in order to internalize positive work values so that a higher level of OCB is achieved. The evidence of this study indicates that individual growth-oriented work norms, organizations and positions oriented work ethics and beliefs, and status and security oriented upwards striving all are important work values in determining citizenship 
and task performance. As such, the findings of this study support the view that unique human resource values and capabilities could be considered as sources that create competitive advantages.

\section{CONCLUSIONS}

The major objective of this study was to examine the impact of work values and individual characteristics on OCB in local and foreign invested firms. The study evidences the impact of gender, employment category, and level of education on OCB and TP, but also shows that there are significant variations between these effects across domestic and foreign invested firms.

Table 3: Impact of Work Values and Demographic Factors on CTP in Local and Foreign Invested Firms

\begin{tabular}{|c|c|c|c|c|c|c|c|c|c|}
\hline \multirow[t]{2}{*}{ Variable } & \multicolumn{3}{|c|}{ CPTIR } & \multicolumn{3}{|c|}{ CPTT } & \multicolumn{3}{|c|}{ TP } \\
\hline & $\begin{array}{l}\text { Overall } \\
\beta\end{array}$ & $\begin{array}{l}\text { Local } \\
\text { Firms } \\
\beta\end{array}$ & $\begin{array}{l}\text { Foreign } \\
\text { invested } \\
\text { firms } \\
\beta\end{array}$ & $\begin{array}{l}\text { Overall } \\
\beta\end{array}$ & $\begin{array}{l}\text { Local } \\
\text { Firms } \\
\beta\end{array}$ & $\begin{array}{l}\text { Foreign- } \\
\text { invested } \\
\text { firms } \\
\beta\end{array}$ & $\begin{array}{l}\text { Overall } \\
\beta\end{array}$ & $\begin{array}{l}\text { Local } \\
\text { Firms } \\
\beta\end{array}$ & $\begin{array}{l}\text { Foreign- } \\
\text { invested } \\
\text { firms } \\
\beta\end{array}$ \\
\hline $\begin{array}{l}\text { Demographic } \\
\text { factor } \Delta R^{2}\end{array}$ & .04 & .03 & $.09 \%$ & $.09 * *$ & $.11 *$ & .07 & .01 & .06 & .01 \\
\hline Gender & .09 & -.03 & $.19 *$ & $.17 *$ & $.16 *$ & .10 & .04 & .09 & .02 \\
\hline Age & .10 & -.01 & .14 & .06 & .05 & .00 & -.01 & -.02 & .01 \\
\hline Experience & -.07 & .02 & .01 & .00 & .00 & .07 & -.02 & -.01 & -.02 \\
\hline $\begin{array}{l}\text { Education- } \\
\text {-A/L }\end{array}$ & -.07 & $-.16^{*}$ & .01 & .01 & .05 & -.05 & .07 & .14 & .01 \\
\hline -Higher & -.07 & -.06 & -.06 & .01 & .13 & -.10 & $.15 *$ & $.27 *$ & .06 \\
\hline $\begin{array}{l}\text { Job Category } \\
\text { - Managerial }\end{array}$ & .09 & .18 & .03 & $.16 *$ & .13 & $.18 *$ & -.03 & -.13 & .06 \\
\hline - Professional & $.12 *$ & .10 & .12 & $.12 *$ & .08 & $.23 *$ & -.01 & -.02 & .04 \\
\hline - Supervisory & .05 & .09 & .01 & .03 & .00 & .06 & -.01 & -.10 & .04 \\
\hline - Clerical & $.18 * *$ & $.16^{*}$ & $.24 *$ & .00 & -.08 & .09 & .01 & -.05 & .06 \\
\hline - Manual & .05 & .04 & .09 & -.01 & -.09 & .07 & -.01 & -.06 & .05 \\
\hline $\begin{array}{l}\text { Work Values } \\
\Delta R^{2}\end{array}$ & $10 * *$ & $14 * *$ & $11 * *$ & $04 * *$ & 08* & 03 & $12 * *$ & $15 * *$ & $11 * *$ \\
\hline Norms & $.21 * *$ & $.20 * *$ & $.27 * *$ & $.13 *$ & $.14^{*}$ & .15 & $.22 * *$ & $.18 *$ & $.26 * *$ \\
\hline Ethics & $.11 *$ & $.21 * *$ & .01 & .04 & $.17 *$ & .08 & $.18 * *$ & $.22 *$ & .11 \\
\hline Extri. Values & .02 & .08 & -.03 & .05 & .06 & .01 & .04 & .12 & -.04 \\
\hline Intrinsicvalue & $.10^{*}$ & .07 & $.16^{*}$ & .09 & .08 & .10 & .03 & .05 & .01 \\
\hline Work LOC & $-.10 *$ & -.11 & -.10 & -.07 & -.04 & -.10 & -.12 & $-.20 *$ & -.04 \\
\hline
\end{tabular}

Significant Beta is shown as $\mathrm{P}<.05^{*}, \mathrm{P}<.01^{* *}, \mathrm{P}<.001 * * *$, Education \& Occupation categories were dummy coded.

The work value dimensions of norms, ethics, intrinsic values, and external locus of control were also found significant in influencing OCB in both local and foreign invested firms. However, differences between foreign invested firms and local firms also found with regard to the impact 
of gender and employment category on CPTT. Clerical employees' involvement in citizenship performance towards interpersonal relationships (CPTIR) was found to be significant both in foreign-invested firms and local firms. In addition, the impact of work ethics on OCB was found to be significant in local companies, while the impact of work norms on OCB was found to be significant in both local and foreign invested firms. In this study, we explored and argued that work values and ethics have strong motivational, psychological, and enduring characteristics. From this conclusion, we could develop a theoretical foundation on which work values could be linked to OCB, which will be useful for future researchers as well. The findings also provide useful theoretical and empirical evidence to understand how strongly individual attributes and work values and ethics affect OCB and contribute to work values and individual attributes theories of OCB. The study also provides some guidance for future researchers and practitioners of HR management.

\section{REFERENCES}

Allison, S.T. \& Messick, D.M. (1990). Social decision heuristics in the use of shared resources. Journal of Behavioral Decision Making, 3, 195-204.

Aldridge, S., David, H, \& Sarah, F. (2002). Social Capital: A discussion paper. London: Performance and Innovation Unit, UK.

Aycan, Z., Al-Hamadi, A.B., Davis, A. \& Budhwar, P. (2007). Cultural orientations and preferences for HRM policies and practices: The case of Oman. International Journal of Human Resource Management, 18(1), 11-32.

Bishop, J.W., Scott, K.D., \& Burroughs, S. M. (2000). Support, commitment, and employee outcomes in a team environment. Journal of Management, 26(6), 1113-1132.

Borman, W.C. and Motowidlo, S.J. (1993). Expanding the criterion domain to include elements of contextual performance. In N. Schmitt, W.C. Borman, \& Associates (Eds.). Personnel Selection in Organizations (pp. 71-89). San Francisco, CA: Jossey-Bass.

Borman, W.C., Penner, L.A., Allen, T.D. \& Motowidlo, S.J. (2001). Personality predictors of citizenship performance. International Journal of Selection and Assessment, 9 (1/2), 52- 69.

Brief, A.P. \& Aldag, R.J. (1994), The study of work values: A call for a more balanced perspective. In I., Borg. \& P.P. Mohler, P.P. (Eds). Trends and Perspectives in Empirical Social Research (pp. 99-124), De Gruyter, New York.

Briggs, S.R. \& Cheek, J.M. (1986). The role of factor analysis in the development and evaluation of personality scales. Journal of Personality, 54: 106-148.

Buchholz, R.A. (1977). The belief structure of managers relative to work concepts measured by a factor analytic model. Personnel Psychology, 30, 567-587.

Buchholz, R. A. (1978). An empirical study of contemporary beliefs about work in American Society. Journal of Applied Psychology, 63(2), 219-227.

Budhwar, P. \& Debrah, Y. (2001). Human Resource Management in developing countries.

Routledge, London.

Chandrakumara, A. \& Budhwar, P.S. (2005). Doing Businesses in Sri Lanka. Thunderbird International Business Review, 47(1), 95-120.

Chandrakumara, A., \& Sparrow, P. (2004). Exploring meaning and values of work orientation as an element of national culture and its impact on HRM policy-practice design choices.

International Journal of Manpower, 25(6), 364-389.

Chiaburu, D.S. \& Byrne, Z.S. (2009). Predicting OCB role definitions: Exchange with the 
organization and psychological attachment. Journal of Business Psychology, 24, 201-214. Claes, R. \& Ruiz-Quintanilla, S.A. (1995). Work meaning patterns in early career. In J.M. Peiro., B. F. Prieto, J.L. Melia \& O. Luque (Eds.). Work and Organizational Psychology: European contribution of the Nineties, UK: Erlbaum: Taylor \& Francis.

Coleman, V.I. \& Borman, W.C. (2000). Investigating the underlying structure of the citizenship performance domain. Human Resource Management Review, 10, 25-44.

Dickson, J.W. \& Buchholz, R.A. (1977). Managerial Beliefs about work in Scotland and the

U.S.A. Journal of Management Studies, 14, 80-101.

Dose, J.J. (1997). Work values: An integrative framework and illustrative application to organizational socialization. Journal of Occupational and Organizational Psychology, 70, 219-240.

England, J.W. \& Harpaz, I. (1990). How work is defined: National contexts and demographic and organizational role influences. Journal of Organizational Behavior, 11, 253-266.

Elizur, D. (1984). Facets of Work Values: A Structural Analysis of Work Outcomes. Journal of Applied Psychology, 69(3), 379-389.

Fariba, L. (2006). A dynamic model interpreting work-related values of multi-faceted cultures: the case of Iran. International Journal of Human Resource Management, 17 (12), 2055- 2073.

Feather, N.T. (1995), Values, valances, and choice: The influence of values on the perceived attractiveness and choice of alternatives. Journal of Personality and Social Psychology, 68(6), 1135-1151.

Fukuyama, F. (1995). Trust: The social virtues and the creation of prosperity. London: Hamish Hamilton.

Furnhan, A. (1996). Attitudinal correlates and demographic predictors of monetary beliefs and Behaviors. Journal of Organizational Behaviour, 17, 375-388.

Furnham, A. (1997). The psychology of behaviour at work: The individual in the organisation.

UK: Psychology Press.

Furnham, A., Petrides, K.B., Tsaousis, I., Pappas, K., \& Garrod, D. (2005). A Cross-cultural investigation into the relationship between personality traits and work values. The Journal of Psychology, 139 (1), 5-32.

Gahan, P. \& Abesekera, L. (2009). What shapes an individual's work values? An integrated model of the relationship between work values, national culture and self-construal. International Journal of Human Resource Management, 20(1), 126-147.

Gagne, M. \& Deci, E.L. (2005). Self-determination theory and work motivation. Journal of Organizational Behvaior, 26, 331-362.

Grant, A.M. (2008). Does intrinsic motivation fuel the prosocial fire? Motivational synergy in predicting persistence performance and productivity. Journal of Applied Psychology,93(1), 4858.

Garg, P.K., \& Parikh, J.J. (1988). Values, designs and development of strategic organization. In

P.N. Khandawalla (Ed.). Social Development, New Delhi: Sage.

Gerhart, B. (2008). Cross cultural management research: Assumptions, evidence, and suggested directions. International Journal of Cross Cultural Management, 8(3), 259-274.

Hackman, J.R., \& Walton, R.E. (1986). Leading groups in organizations. In P.S. Goodman (Ed.). Designing Effective Work Groups (pp.72-119), San Francisco: Jossey-Bass.

Harpaz, I. (1986). The behavioral structure of the meaning of working. Human Relations, 26, 595614.

Hartman, J.B. \& Samra, Y.M. (2008). Impact of personal values and innovativeness on hedonic 
and utilitarian aspects of web use. International Journal of Management, 25(1), 77-99.

Heller, F. (1997). Work Ethic. In A Sorge \& M. Warner (Eds.), the IEBM Handbook of Organizational Behavior (pp. 453-457), London: International Thomson Business Press.

Herzberg, F. (1966). Work and nature of man. Chicago: World.

Hunt, S.T. (2002). On the virtues of staying 'inside the box': Does organizational citizenship behaviour detract from performance in Taylorist' jobs. International Journal of Selection and Assessment, 10(1/2), 152-159.

Katz, D. \& Kahn, R.L. (1996). The social psychology of organizations. New York, NY: Wiley.

Kidder, D.L (2002). The influence of gender on the performance of organizational citizenship behavior. Journal of Management, 166, 1-20.

Kirkman, B.L., Lowe, K.B. \& Gibson, C.B. (2006). A quarter century of culture's consequences: A review of empirical research incorporating Hofstede's cultural values framework. Journal of International Business Studies, 37, 285-320.

Konovsk, M.A. and Organ, D.W. (1996). Dispositional and contextual determinant of OCB. Journal of Organizational Behavior, 17, 253-266.

Korsgaard, M.A; Meglino, B.M, Lester, S.W, \& Jeong, S.S. (2010). Paying you back or Paying me forward: Understanding rewarded and unrewarded OCB. Journal of Applied Psychology, 95(20), 227-290.

Kluckhohn, F.R. \& Strodbeck, F.L. (1961). Variations in value orientations. New York: Harper \& Row.

MacKenzie, S.B., Podsakoff, P.M. \& Fetter, R. (1991). Organizational Citizenship behavior and objective productivity as determinant of managerial evaluation of sales persons' performance. Organizational Behavior and Human Decision Processes, 50, 123-150.

Merrens, M.R. \& Garrett, J.B. (1975). The Protestant ethic scale as a predictor of repetitive work performance. Journal of Applied Psychology, 60(1), 125-127.

Moon, H., Kamdar, D., Mayer, D.M. \& Takeuchi, R. (2008). Me or We? The role of personality and justice as other centered antecedents to innovative citizenship behavior within organization. Journal of Applied Psychology, 93(1), 84-94.

Motowidlo, S.J. and Borman, W.C. \& Schmit, M.J. (1997). A theory of individual differences in task and contextual performance. Human Performance, 10: 71-83.

Motowidlo, S.J. \& Van Scotter, J.R. (1994). Evidence that task performance should be distinguished from contextual performance. Journal of Applied Psychology, 79(4), 475- 480.

MOW International Research Team (1987). The meaning of working. London: Academic Press. Nanayakkara, G. (1992, 1988). Culture and Management in Sri Lanka, Sri Lanka: Postgraduate

Institute of Management, University of Sri Jayewardenepura.

Noon, M. \& Blyton, P.(1997). The realities of work. London: MacMillan Business. Organ, D.W. (1988). Organizational citizenship behavior: The good soldier syndrome.

Lexington,

MA: Lexington Books.

Organ, D.W. \& Yeon Lee, J. (2008). Organizational citizenship behavior, transaction cost economics, and the Flat world hypotheses. In R. J. Burke \& C. L. Cooper (Eds.), Building more effective organizations, Cambridge University Press, UK.

Paine, J.B. \& Organ, D.W. (2000). The cultural matrix of organizational citizenship behavior: some preliminary conceptual and empirical observations. Human Resources Management Review, 10(1), 45-59. 
Pantoja, E. (1999). Exploring the concept of social capital and its relevance for community based development: the case of mining areas in Orissa, India, South Asia Infrastructure Unit. The World Bank.

Pelled, L.P. \& Hill, K.D. (1997). Employee work values and organizational attachment in North Mexican maquiladoras. The International Journal of Human Resource Management, 8(4), 495505.

Podsakoff, N.P., Whiting, S.W., Podsakoff, P.M., \& Blume, B.D. (2009). Individual and organizational level consequences of OCB: A meta-analysis. Journal of Applied Psychology, 94(1), 122-141.

Podsakoff, P.M., MacKenzie, S.B., Paine, J.B., \& Bachrach, D.D. (2000). Organizational citizenship behavior: Critical review of the theoretical and empirical literature and suggestions for future research. Journal of Management, 26(3), 513-563.

Preston, R. (1987). The future of Christian Ethics, London: SCM.

Reitz, H. J. \& Jewell, L.N. (1979). Sex, locus of control, and job involvement: A six-country investigation. Academy of Management Journal, 22, 72-80.

Rokeach, M. (1973). The Nature of Human Values. New York: Free Press.

Roe, R.A. \& Ester, P. (1999). Values and work: Empirical findings and theoretical perspective. Applied Psychology: An International Review, 48(1), 1-21.

Ros, M., Schwartz, S.H., \& Surkiss, S. (1999). Basic individual values, work values, and the meaning of work. Applied Psychology: An International Review, 48(1), 49-71.

Ruiz-Quintanilla, S.A. \& England, G.W. (1996). How working is defined: Structure and stability. Journal of Organizational Behavior, 17, 515-540.

Sagie, A., Elizur, D. \& Koslowsky, M. (1996). Work values: a theoretical overview and a model of their effects. Journal of Organizational Behavior, 17, 503-514.

Sagie, A. \& Weisberg, J. (1996). A structural analysis of behavior in work situations shared by group members. The Journal of Psychology, 130(4), 371-382.

Sekaran, U (2000). Research methods for business: A skill building approach. (Third Ed), Wiley: New York: NY.

Smeesters, D., Warlop, L., Van Avermaet, E., Corneille, O. \& Yzerbyt, V. (2003). Do not prime hawks with doves: The interplay of construct activation and consistency of social value orientation on cooperative behavior. Journal of Personality and Social Psychology, 84(5), 972-987.

Smeesters, D., Wheeler, S.C. \& Kay, A.C. (2009). The role of interpersonal perception in the prime-to behaviors pathway. Journal of Personality and Social Psychology, 96(2), 395- 414.

Smith, C.A., Organ, D.W. \& Near, J.P. (1983). Organizational citizenship behavior: its nature and antecedents. Journal of Applied Psychology, 68(4), 653-663.

Sparrow, P.R. (2006) International management: some key challenges for industrial and organizational psychology. International Review of Industrial and Organizational Psychology, 21, 189-266.

Sparrow, P., \& Budhwar, P.S. (1997). Competition and change: Mapping the Indian HRM recipe against worldwide patterns. Journal of World Business, 32(3).

Sparrow, P.R. \& Wu, P. (1998). How much do national value orientations really matter?

Predicting HRM preferences of Taiwanese employees. Employee Relations, 20(1), 26-56.

Spector, P. (1982). Behavior in organizations as a function of employees' locus of control.

Psychological Bulletin, 91, 482-497.

Singelis, T.M., Triandis, H.C., Bhawuk, D., \& Gelfand, M.J. (1995). Horizontal and vertical 
dimensions of individualism and collectivism: a theoretical and measurement refinement. Cross-Cultural Research, The Journal of Comparative Social Science, 29, 240-275.

Taris, R., \& Feij, J.A. (2001). Longitudinal examination of the relationship between suppliesvalues fit and work outcomes. Applied Psychology: International Review, 50(1), 52-80.

Terry, D.J., Hogg, M.A. \& White, K.M. (1999). The theory of planned behavior: Self-identity, social identity and group norms. British Journal of Social Psychology, 38, 225-244.

Tierney, P., Bauer, T.N. \& Potter, R.C. (2002). Extra-role behavior among Mexican employees: The impact of LMX, group acceptance, and job attitudes. International Journal of Selection and Assessment, 10(4), 292-303.

Wayne, S.J., Shore, L.M., \& Liden, R.C. (1997). Perceived organizational support and leadermember exchange: a social exchange perspective. Academy of Management Journal, 40(1), 82- 111.

Werner, J.M. (1994). Dimensions that make a difference: examining the impact of in-role and extra-role behaviours on supervisory ratings. Journal of Applied Psychology, 79, 98-107.

Wollack, S., Goodale, J.G., Wijting, J.P. \& Smith, P.C. (1971). Development of survey of work values. Journal of Applied Psychology, 55(40), 331-338. 